Erratum

\title{
Erratum to "Punicalin Alleviates OGD/R-Triggered Cell Injury via TGF- $\beta$-Mediated Oxidative Stress and Cell Cycle in Neuroblastoma Cells SH-SY5Y
}

\author{
Tiansong Yang, ${ }^{1}$ Qingyong Wang, ${ }^{2}$ Yuanyuan Qu, ${ }^{2}$ Yan Liu, ${ }^{1}$ Chuwen Feng, ${ }^{1}$ Yulin Wang, \\ Weibo Sun, ${ }^{3}$ Zhongren Sun $\mathbb{D}^{2},{ }^{2}$ and Yulan $\mathrm{Zhu}^{4}$ \\ ${ }^{1}$ First Affiliated Hospital, Heilongjiang University of Chinese Medicine, Harbin, China \\ ${ }^{2}$ Heilongjiang University of Chinese Medicine, Harbin, China \\ ${ }^{3}$ Harbin Medical University, Harbin, China \\ ${ }^{4}$ Department of Neurology, The Second Affiliated Hospital of Harbin Medical University, Harbin, China \\ Correspondence should be addressed to Zhongren Sun; sunzhong_ren@163.com
}

Received 11 April 2021; Accepted 11 April 2021; Published 28 April 2021

Copyright $(92021$ Tiansong Yang et al. This is an open access article distributed under the Creative Commons Attribution License, which permits unrestricted use, distribution, and reproduction in any medium, provided the original work is properly cited.

In the article titled "Punicalin Alleviates OGD/R-Triggered Cell Injury via TGF- $\beta$-Mediated Oxidative Stress and Cell Cycle in Neuroblastoma Cells SH-SY5Y" [1], the Author's Contributions section is missing. The corrected section appears as follows:

\section{Authors' Contributions}

Tiansong Yang, Qingyong Wang, Yuanyuan Qu, and Yan Liu contributed equally to this work.

The error was introduced during the production process of the article, and Hindawi apologies for this mistake.

\section{References}

[1] T. Yang, Q. Wang, Y. Qu et al., "Punicalin Alleviates OGD/RTriggered Cell Injury via TGF- $\beta$-Mediated Oxidative Stress and Cell Cycle in Neuroblastoma Cells SH-SY5Y," Evidence-Based Complementary and Alternative Medicine, vol. 2021, Article ID 6671282, 11 pages, 2021. 